\title{
Cardiovascular pre-participation screening in young athletes: Recommendations of the Association of European Paediatric Cardiology - CORRIGENDUM
}

Peter Fritsch, Robert Dalla Pozza, Doris Ehringer-Schetitska, Eero Jokinen, Vesna Herceg, Erzsebet Hidvegi, Renate Oberhoffer, Andreas Petropoulos, on behalf of the Association for European Paediatric Cardiology Working Group Cardiovascular Prevention

doi:10.1017/S1047951117001305, Published by Cambridge University Press, 9 August 2017.

The authors apologise for the incorrect alphabetical order of the author names in this published article. The author names should have appeared as follows:

Peter Fritsch, Doris Ehringer-Schetitska, Robert Dalla Pozza, Eero Jokinen, Vesna Herceg, Erzsebet Hidvegi, Andreas Petropoulos, Renate Oberhoffer on behalf of the Association for European Paediatric Cardiology Working Group Cardiovascular Prevention

\section{Reference}

Peter Fritsch, Robert Dalla Pozza, Doris Ehringer-Schetitska, Eero Jokinen, Vesna Herceg, Erzsebet Hidvegi, Renate Oberhoffer, Andreas Petropoulos on behalf of the Association for European Paediatric Cardiology Working Group Cardiovascular Prevention. Cardiovascular pre-participation screening in young athletes: Recommendations of the Association of European Paediatric Cardiology. Cardiol Young. Published by Cambridge University Press, 9 August 2017. doi:10.1017/S1047951117001305. 